\title{
A PROTEÇÃO DO TRABALHO DA MULHER E A PERPETUAÇÃO DO ESTEREÓTIPO DE GÊNERO \\ Os dispositivos legais que diferenciam homens e mulheres e seu sentido na atualidade
}

Dissertação de Mestrado

Orientador: Professor Associado Dr. Estevão Mallet

UNIVERSIDADE DE SÃO PAULO

FACULDADE DE DIREITO

São Paulo, SP

2019 


\title{
A PROTEÇÃO dO TRABALHO dA MULHER E A PERPETUAÇÃO DO ESTEREÓTIPO DE GÊNERO
}

Os dispositivos legais que diferenciam homens e mulheres e seu sentido na atualidade

\begin{abstract}
Dissertação apresentada à Banca Examinadora do Programa de PósGraduação em Direito da Faculdade de Direito da Universidade de São Paulo, como exigência parcial para a obtenção do título de Mestre em Direito, na área de concentração de Direito do Trabalho e da Seguridade Social, sob a orientação do Professor Associado Dr. Estevão Mallet.
\end{abstract}

\section{UNIVERSIDADE DE SÃO PAULO \\ FACULDADE DE DIREITO}

São Paulo, SP 



\section{FICHA CATALOGRÁFICA}

Autorizo a reprodução e divulgação total ou parcial deste trabalho, por qualquer meio convencional ou eletrônico, para fins de estudo e pesquisa, desde que citada a fonte.

Serviço de Processos Técnicos da Biblioteca da Faculdade de Direito da Universidade de São Paulo

Marques, Marina Dutra

A proteção do trabalho da mulher e a perpetuação do estereótipo de gênero: Os dispositivos legais que diferenciam homens e mulheres e seu sentido na atualidade / Marina Dutra Marques. - São Paulo: M. D. Marques, 2019.

$146 \mathrm{f.} ; 30 \mathrm{~cm}$.

Dissertação (Mestrado) - Universidade de São Paulo, USP, Programa de Pós-Graduação em Direito, Direito do Trabalho e da Seguridade Social, 2019.

Orientador: Estevão Mallet.

1. Trabalho. 2. Estereótipo. 3. Gênero. 4. Direito da Mulher. 5. Proteção da Mulher. I. Mallet, Estevão. II. Título. 



\section{FOLHA DE APROVAÇÃO}

Marques, M. D. A Proteção do Trabalho da Mulher e a Perpetuação do Estereótipo de Gênero: Os dispositivos legais que diferenciam homens e mulheres e seu sentido na atualidade. 2019. Dissertação (Mestrado) Faculdade de Direito, Universidade de São Paulo, 2019.

BANCA EXAMINADORA

MALLET, Estevão (FACULDADE DE DIREITO/USP) 

À Manu, Luísa, Olívia, Pipa, Alice, Betina, Maitê e tantas outras por vir 

A gender line... helps to keep women not on a pedestal, but in a cage.

(Ruth Bader Ginsburg) 



\section{AGRADECIMENTOS}

Primeiramente, agradeço a todas as mulheres que me precederam e lutaram pelo movimento feminista como souberam ou puderam, refinando os debates até o ponto em que se encontram; as imagens recentes do cordão humano na Índia me deram forças quando este estudo pareceu desconectado com a realidade do Brasil.

Agradeço, de forma particular, às mulheres da minha vida: minha avó, minha mãe e minha irmã; cada uma, a sua maneira, quebrou padrões e me ensinou que não existe apenas uma forma de abraçar as oportunidades e vencer os desafios.

Agradeço também a toda minha família, fonte de solidez e estabilidade, incluindo no conceito de família aqueles amigos que também dividem comigo o afeto e a incondicionalidade que conectam pessoas da forma mais profunda.

Agradeço, especialmente, às duas novas amigas trazidas pelo mestrado, que partilharam comigo todas as conquistas e angústias dessa fase de descobertas acadêmicas e pessoais que nos trouxe até o depósito desta dissertação juntas, cansadas e realizadas.

Agradeço aos companheiros de todos os dias, sócios, advogados e estagiários do escritório onde trabalho, aprendo e me divirto, pelos conselhos, livros, ideias, discussões mas, especialmente, pelo apoio e espírito de equipe que não deixam de me impressionar.

Agradeço ao professor orientador deste estudo, fonte de inspiração não só para a escrita do trabalho, mas também para a atuação acadêmica, comprometimento com o aprendizado e cordialidade em qualquer ocasião. Agradeço também à professora que motivou o meu interesse pelo tema dos estereótipos de gênero, tema este que eu sequer conhecia antes de conhecê-la.

Agradeço aos livros. Agradeço à música. Gracias a la vida, que me ha dado tanto. 



\section{RESUMO}

O tema desta pesquisa é a proteção do trabalho da mulher e a perpetuação do estereótipo de gênero. O objetivo é analisar o papel do estereótipo de gênero na criação das normas trabalhistas que diferenciam homens e mulheres no Brasil; as tendências de transformação das normas no tempo; o sentido das normas na atualidade, à luz das transformações sociais desde a sua promulgação; a capacidade da norma de assegurar a transformação ou perpetuação do status quo; a compatibilidade das normas com as previsões constitucionais e convencionais em voga; e alternativas para atingimento da igualdade de fato. Assim, a pesquisa analisa a legislação protetora do trabalho da mulher, bem como normas previdenciárias correlatas, frente ao conceito e à classificação do estereótipo de gênero conforme os ensinamentos de Rebecca J. Cook e Simone Cusack, além das pertinentes normas internacionais, constitucionais e supralegais, recomendações e publicações de organismos internacionais sobre os direitos humanos, da mulher e do trabalho, dados estatísticos, doutrina e jurisprudência. É traçado paralelo entre os estereótipos de gênero e as normas sobre saúde e segurança, normas de proteção à maternidade e normas previdenciárias correlatas. Em separado, são classificadas as normas que tem condão de ações afirmativas. As normas que tem carga de estereótipo de gênero e não constituem medidas especiais de caráter temporário destinadas a acelerar a igualdade de fato são interpretadas como inconstitucionais, bem como afrontosas às convenções internacionais ratificadas pelo Brasil. Assim, seguindo a lógica das tendências normativas verificadas nas últimas décadas, são analisadas as hipóteses de nivelamento de direitos entre os gêneros.

Palavras-chave: trabalho; estereótipo; gênero; direito da mulher; proteção da mulher. 



\begin{abstract}
The focus of this dissertation is the protection of women's work and the perpetuation of the gender stereotype. The goal is to analyze the role of gender stereotype in the creation of labor standards that differentiate men and women in Brazil; trends in standards transformation over time; the purpose of these norms in the present, in the light of the social changes since their enactment; the standards' ability to ensure social transformation or perpetuation of the status quo; the compatibility of the standards with the current constitutional and conventional bases; and alternatives for attaining de facto equality. Thus, the research analyzes the protective legislation of women's work, as well as related social security norms, against the concept and classification of the gender stereotype according to the lessons of Rebecca J. Cook and Simone Cusack. In addition to the relevant international, constitutional and supra-legal norms, recommendations and publications of international organizations on human rights, women and labor, statistical data, doctrine, and jurisprudence. A parallel is drawn between gender stereotypes and norms on health and safety, maternity protection and related social security legislation. The norms with affirmative action characteristics are classified separately. Norms that have a gender stereotype burden and are not special temporary measures designed to accelerate de facto equality are interpreted as unconstitutional as well as being contrary to international conventions ratified by Brazil. Thus, following the logic of the normative tendencies verified in the last decades, the hypotheses of the leveling of rights between the genders are analyzed.
\end{abstract}

Keywords: labor; gender; stereotype; women's rights; protection of women. 



\section{LISTA DE ILUSTRAÇÕES}

Figura 1 - Desempenho global do Relatório Global de Desigualdade de Gênero. Fonte: Fórum Econômico Mundial (2017). 29

Figura 2 - Relação entre qualificação educacional e participação no mercado de trabalho. Fonte: Fórum Econômico Mundial (2016).

Figura 3 - Média global dos ganhos mundiais. Fonte: Fórum Econômico Mundial (2016).

Figura 4 - A Jornada de trabalho de homens e mulheres. Fonte: Fórum Econômico Mundial (2016). 32

Figura 5 - Média de horas dedicadas aos cuidados de pessoas e/ou afazeres domésticos por pessoas ocupadas, por sexo (horas semanais); dados de 2016. Fonte: IBGE, 2018. 116

Figura 6 -Proporção de ocupados em trabalho por tempo parcial, na semana de referência, por sexo (\%). Fonte: IBGE, 2016. 117

Figura 7 - Rendimento habitual médio mensal de todos os trabalhos e razão de rendimentos, por sexo. Fonte: IBGE, 2018. 



\section{LISTA DE TABELAS}

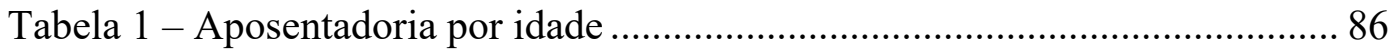

Tabela 2 - Aposentadoria tempo de serviço............................................................ 86

Tabela 3 - Licença parental nos países nórdicos................................................ 112 



\section{LISTA DE ABREVIATURAS E SIGLAS}

\begin{tabular}{|c|c|}
\hline $\mathrm{ADCT}$ & Ato das Disposições Constitucionais Transitórias \\
\hline $\mathrm{CEDH}$ & Convenção Europeia dos Direitos Humanos \\
\hline \multirow[t]{2}{*}{ CEEP } & European Centre of Employers and Enterprises providing \\
\hline & Public Services and Services of general interest \\
\hline $\mathrm{CF}$ & Constituição da República Federativa do Brasil \\
\hline CLT & Consolidação das Leis do Trabalho \\
\hline DNSHT & Departamento Nacional de Segurança e Higiene do Trabalho \\
\hline \multirow[t]{3}{*}{ EACDH } & Escritório do Alto Comissário das Nações Unidas para os \\
\hline & Direitos Humanos (Office of the High Commissioner for \\
\hline & Human Rights) \\
\hline EPI & Equipamentos de Proteção Individual \\
\hline EsPCEx & Escola Preparatória de Cadetes do Exército \\
\hline ETUC & European Trade Union Confederation \\
\hline IBGE & Instituto Brasileiro de Geografia e Estatística (IBGE) \\
\hline LGBT & $\begin{array}{l}\text { Lésbicas, Gays, Bissexuais, Travestis, Transexuais e } \\
\text { Transgêneros }\end{array}$ \\
\hline ONU & Organização das Nações Unidas \\
\hline TST & Tribunal Superior do Trabalho \\
\hline STF & Supremo Tribunal Federal \\
\hline OAE & Organização dos Estados Americanos \\
\hline OIT & Organização Internacional do Trabalho \\
\hline OMS & Organização Mundial da Saúde \\
\hline \multirow[t]{3}{*}{ ONU MULHERES } & Entidade das Nações Unidas para a Igualdade de Gênero e o \\
\hline & Empoderamento das Mulheres (United Nations Entity for \\
\hline & Gender Equality and the Empowerment of Women) \\
\hline UNICE & Union of Industrial and Employers' Confederation of Europe \\
\hline
\end{tabular}





\section{ÍNDICE}

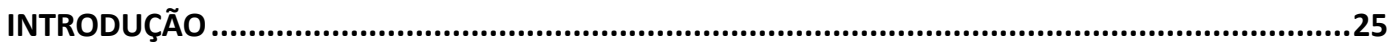

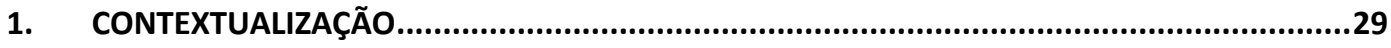

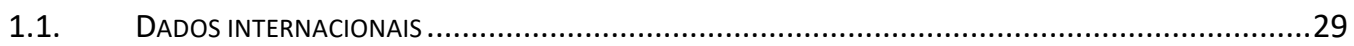

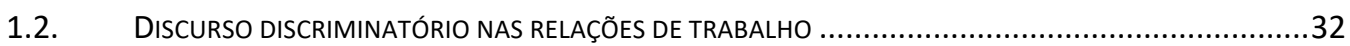

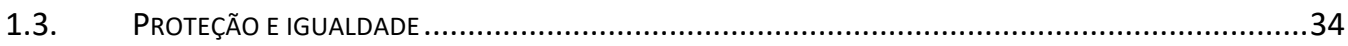

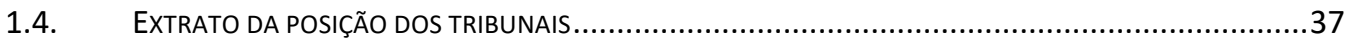

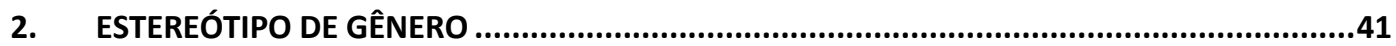

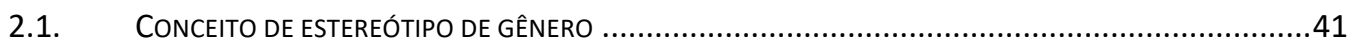

2.2. ESTEREÓTIPO DE GÊNERO COMO FORMA DE DISCRIMINAÇÃO..................................................43

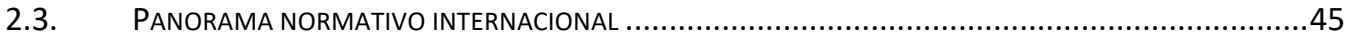

2.3.1. Organização das Nações Unidas (ONU)..............................................................45

2.3.2. Organização Internacional do Trabalho (OIT) ......................................................49

2.3.3. Organização dos Estados Americanos (OEA) ....................................................52

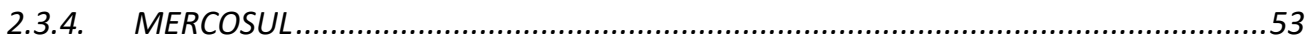

2.3.5. Outras normas internacionais ..........................................................................53

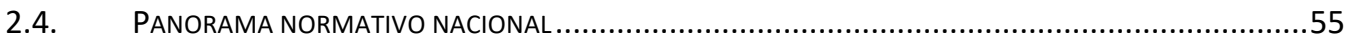

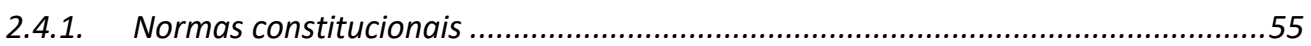

2.4.2. Normas infraconstitucionais.......................................................................56

3. LEGISLAÇÃO PROTETORA DO TRABALHO DA MULHER........................................................61

3.1. NORMAS SOBRE A SAÚDE E SEGURANÇA DO TRABALHO .....................................................62

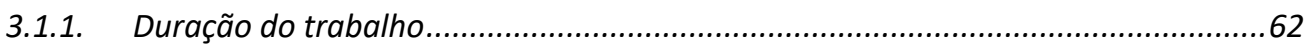

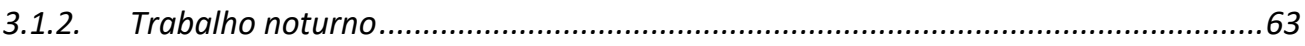

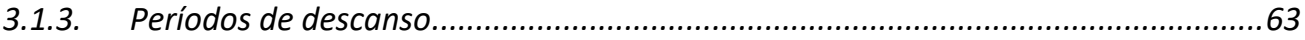

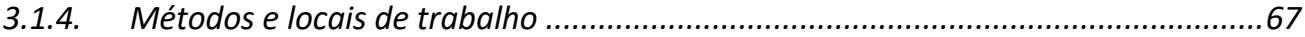

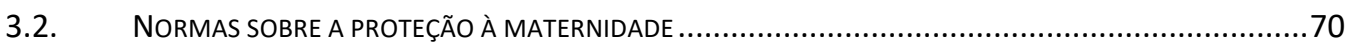

3.3. NORMAS SOBRE A DISCRIMINAÇÃO DA MULHER NO MERCADO DE TRABALHO ................................78

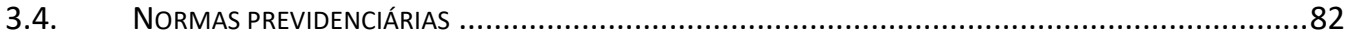

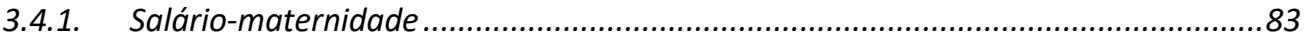

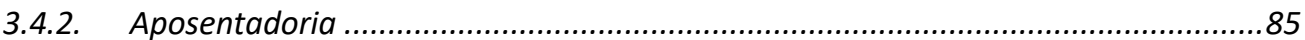

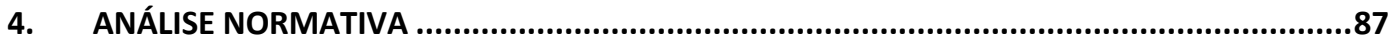

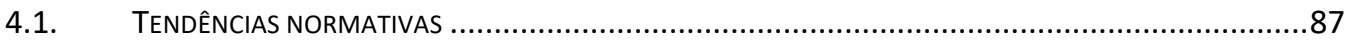

4.1.1. Movimento de subtração das normas protetoras ...............................................87 
4.1.2. Movimento de alteração do sujeito das normas protetoras.................................90

4.1.3. Movimento de expansão das normas protetoras ..............................................92

4.2. PAPEL DO ESTEREÓTIPO DE GÊNERO NAS NORMAS PROTETORAS ...............................................94

4.2.1. Intersecção entre normas de saúde e segurança e estereótipo de sexo.................95

4.2.2. Interseç̧ão entre normas de proteção à maternidade e estereótipo do papel do sexo 98

4.2.3. Intersecção entre normas previdenciárias e estereótipo de papel de sexo............104

4.3. NORMAS PROTETORAS COMO AÇÕES AFIRMATIVAS ............................................................106

4.3.1. Normas sobre discriminação da mulher no mercado de trabalho.........................106

4.3.2. Normas de saúde e segurança, de proteção à maternidade e previdenciárias .....107

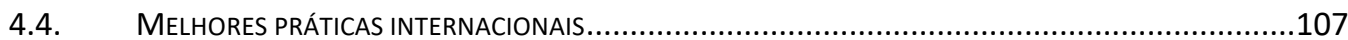

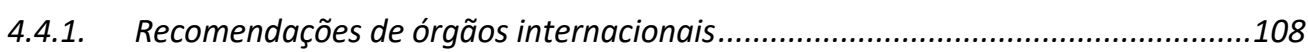

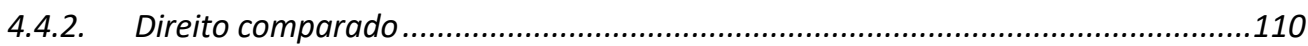

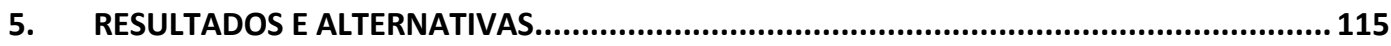

5.1. RESULTADOS DA PERPETUAÇÃO DO ESTEREÓTIPO DE GÊNERO …............................................115

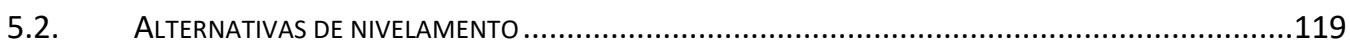

5.2.1. Movimento de subtração das normas protetoras .............................................120

5.2.2. Movimento de alteração do sujeito das normas protetoras................................122

5.2.3. Movimento de expansão das normas protetoras ..............................................124

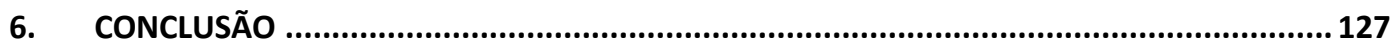

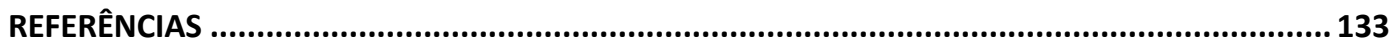

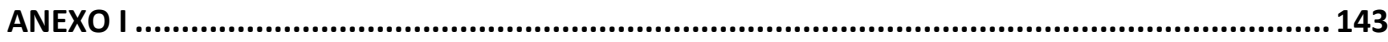




\section{INTRODUÇÃO}

O tema desta pesquisa, como indica o próprio título, é a proteção do trabalho da mulher e a perpetuação do estereótipo de gênero. O subtítulo foi escolhido para demonstrar que os dispositivos legais que diferenciam homens e mulheres serão objeto desta análise com o propósito de entender o seu sentido na atualidade. O recorte metodológico se dá para analisar a legislação trabalhista, bem como previdenciária correlata, ainda que se reconheça a imensa relevância de outros diversos aspectos de políticas públicas e costumes sociais para a perpetuação do estereótipo de gênero. Ademais, apesar de ser extremamente interessante e (mais do que nunca) valoroso estudar as questões afeitas à comunidade de Lésbicas, Gays, Bissexuais, Travestis, Transexuais e Transgêneros (LGBT) e as novas formas de família, acertadamente reconhecidas pela jurisprudência moderna, elas não serão o foco deste trabalho, ainda que possam ser mencionadas pontualmente. Também não serão tratados assuntos relacionados a pessoas hermafroditas, assim como mulheres do sexo feminino que não carregam as supostas especificidades biológicas naturais, como o órgão reprodutor.

A importância da discussão sobre estereótipos de gênero, no contexto apresentado, ocorre, pois estereotipar é inegavelmente parte da natureza humana; é uma forma de categorizar indivíduos, por vezes inconscientemente, entre diferentes grupos ou tipos, em parte, para simplificar o mundo que nos envolve, sem considerar as habilidades, necessidades, desejos e circunstâncias individuais de cada pessoa (Cook \& Cusack, 2010). Todavia, o estereótipo de gênero, objeto deste trabalho, é prejudicial quando limita a capacidade do ser humano de desenvolver suas habilidades pessoais, perseguir suas carreiras profissionais e fazer escolhas sobre suas vidas e planos de vida (EACDH, 2013).

As estatísticas mostram que ainda existe um longo caminho a ser percorrido para a conquista da plena igualdade de gênero, especialmente no tocante ao trabalho e emprego. A despeito da evolução observada no último século, inclusive no que tange à educação, as mulheres continuam afastadas das melhores oportunidades remuneradas e sobrecarregadas com tarefas não remuneradas. Ademais, persiste o discurso discriminatório e aberto contra a empregabilidade da mulher, emanado desde as primeiras discussões do Código de Trabalho de 1917. Além de persistir o debate generalizado sobre a constitucionalidade ou não das normas diferenciadoras de homens e mulheres em matéria de trabalho frente ao princípio da igualdade quase 30 (trinta) anos após o início da "nova" ordem constitucional - debate esse intensificado pela promulgação da chamada "Reforma Trabalhista". Todavia, 
pouco se fala da convencionalidade dessas previsões ou de sua relação com a perpetuação do estereótipo de gênero que, de acordo com o relatório comissionado do Escritório do Alto Comissário das Nações Unidas para os Direitos Humanos (EACDH) (Office of the High Commissioner for Human Rights - OHCHR) intitulado de Estereótipo de Gênero como uma Violação aos Direitos Humanos (Gender Stereotyping as a Human Rights Violation), é uma causa disseminada de violação aos direitos humanos.

Ainda que a Constituição da República Federativa do Brasil de 1988 (Brasil, 1988) não seja específica ao tratar de estereótipos de gênero, cria todo um arcabouço de comandos antidiscriminatórios e protetivos que trazem abertura à referida questão. De início, o artigo $3^{\circ}$, IV proíbe genericamente qualquer forma de discriminação. Também o artigo $5^{\circ}$, caput determina que todos são iguais perante a lei, sem distinção de qualquer natureza. Nos termos da Constituição, seu inciso primeiro determina categoricamente que homens e mulheres são iguais em direitos e obrigações.

No âmbito do trabalho, especificamente, o artigo $7^{\circ}, \mathrm{XXX}$ da $\mathrm{CF}$ determina a proibição de diferença de salários, de exercício de funções e de critério de admissão por motivo de sexo, idade, cor ou estado civil. Ao lado dos comandos antidiscriminatórios, estipulou-se no artigo $7^{\circ}, \mathrm{XX}$, "a proteção do mercado de trabalho da mulher mediante incentivos específicos, nos termos da lei”. Nessa linha, há de se entender que a Constituição somente permite a prática diferenciada desde que efetivamente direcionada à proteção ou ampliação do mercado de trabalho da mulher.

Junte-se a isso as normas internacionais. Nada obstante toda proteção internacional ao ser humano, independentemente de gênero, a mulher continua sendo objeto de grandes discriminações. Assim, foram criados instrumentos específicos com o intuito de atingir a igualdade de gênero de forma irrestrita, principalmente a Convenção sobre a Eliminação de Todas as Formas de Discriminação contra a Mulher, adotada em 1979 pela Assembleia Geral da ONU, com texto publicado oficialmente em língua nacional pelo Decreto 89.460/1984ํ․ Ela reconhece que, para alcançar a plena igualdade entre o homem e a mulher, é necessário modificar o papel tradicional de ambos na sociedade e na família.

A Convenção em comento também determina as principais obrigações dos EstadosParte com o objetivo eliminar a discriminação contra a mulher, até o compromisso de "adotar todas as medidas adequadas, inclusive de caráter legislativo, para modificar ou derrogar leis, regulamentos, usos e práticas que constituam discriminação contra a mulher”

\footnotetext{
1 Posteriormente revogado e substituído pelo Decreto 4.337/2002, que removeu reservas anteriormente estabelecidas.
} 
(artigo 2 ${ }^{\circ}$, "f"). Ademais, a norma traz à baila, explicitamente, a questão do estereótipo de gênero como parte do contexto dessa discriminação. Assim, em interpretação conjunta dos dispositivos, entende-se que "leis, regulamentos, usos e práticas baseados na ideia da inferioridade ou superioridade de qualquer um dos sexos ou em funções estereotipadas de homens e mulheres devem ser modificados ou derrogados" (Cook \& Cusack, 2010, p. 5). Por outro lado, o artigo $4^{\mathrm{o}}$ da Convenção trata, de forma apartada, da adoção de medidas especiais de caráter temporário destinadas a alcançar a igualdade de fato entre homens e mulheres.

Nesse cenário, o tema deste estudo será limitado à análise de normas trabalhistas brasileiras de proteção do trabalho da mulher, bem como previdenciárias correlatas, para investigar: (a) o papel do estereótipo de gênero na criação das normas; (b) as tendências de transformação das normas no tempo; (c) o sentido das normas na atualidade, à luz das transformações sociais desde a sua promulgação; (d) a capacidade da norma de assegurar a transformação ou perpetuação do status quo; (e) a compatibilidade das normas com as previsões constitucionais e convencionais em voga; e (f) alternativas para atingimento da igualdade de fato.

Assim, a dissertação será construída para responder as seguintes questões principais: (i) as normas que diferenciam o trabalho do homem e da mulher têm poder de transformação social, ou perpetuam status quo da desigualdade e do estereótipo de gênero?; e (ii) tais normas são alinhadas com a ratio legis da $\mathrm{CF}$ e das convenções internacionais ratificadas pelo Brasil, bem como com as melhores práticas internacionais para atingimento da igualdade de gênero?

Sob o contexto já delimitado, pretende-se analisar o Capítulo III da Consolidação das Leis do Trabalho (CLT), intitulado "Da Proteção do Trabalho da Mulher", bem como as leis que alteraram suas disposições desde a promulgação (inclusive a Lei 13.467/217, que trouxe a chamada "Reforma Trabalhista"), além das normas administrativas e entendimentos jurisprudenciais pertinentes à matéria ali tratada. Também serão analisadas a Lei 9.029/1995 (apesar de deslocada da CLT, ela trata de práticas discriminatórias e limitativas para efeitos de acesso e manutenção da relação de emprego) e previsões esparsas, como aquelas do Ato das Disposições Constitucionais Transitórias (ADCT) sobre a estabilidade da gestante e a licença paternidade. Ademais, é pertinente aludir às normas previdenciárias, insertas na Lei 8.213/1991, quanto ao salário gestante e aposentadoria.

Esse conjunto normativo será cotejado conforme a seguinte metodologia: serão analisadas as normas trabalhistas que protegem o trabalho da mulher, bem como normas 
previdenciárias correlatas (acima enumeradas), frente às normas internacionais, constitucionais e supralegais pertinentes, além de recomendações e publicações de organismos internacionais sobre os direitos humanos, da mulher e do trabalho, como o relatório Estereótipo de Gênero como uma Violação aos Direitos Humanos (EACDH, 2013), bem como a doutrina e a jurisprudência. Ademais, serão utilizados dados estatísticos que se mostrem relevantes para determinar as tendências globais e nacionais relativas ao trabalho da mulher, especialmente aqueles publicados por órgãos internacionais, a exemplo do Relatório Global de Desigualdade de Gênero (Global Gender Gap Report) do Fórum Econômico Mundial (2016; 2017).

Em relação ao conceito e classificações do estereótipo de gênero, será adotada a doutrina de Rebecca J. Cook e Simone Cusack (2010), por ser percursora e aclamada na matéria, e por ter baseado o supramencionado relatório do EACDH (2013). Sua doutrina foi também utilizada pela Relatora Especial da ONU Gabriella Knaul no Report of the Special Rapporteur on the Independence of Judges and Lawyers (Knaul, 2011) e "citada com aprovação - embora indireta - no Grupo de Trabalho das Nações Unidas sobre a Questão da Discriminação contra as Mulheres na Lei e na Prática (UN Working Group on the Issue of Discrimination against Women in Law and in Practice)" (EACDH, 2013, p. 8).

Para tanto, é importante apresentar uma contextualização sobre o assunto, ainda que sumariamente, conforme os dados encontrados em pesquisas internacionais, o discurso discriminatório ainda propagado no Brasil, os conceitos de proteção e igualdade no ordenamento jurídico pátrio e um extrato da posição dos tribunais no Capítulo 1. Após, o Capítulo 2 trará breve explicação sobre os conceitos que rodeiam o estereótipo de gênero; o Capítulo 3 disporá sobre a legislação sob análise; o Capítulo 4 fará a comunicação entre os Capítulos 2 e 3, relacionando tais normas com os diferentes tipos de estereótipo, ou não; e, por fim, o Capítulo 5 tratará sobre os resultados da perpetuação do estereótipo de gênero e as possíveis alternativas para o nivelamento de direitos entre homens e mulheres. 


\section{CONCLUSÃO}

A desigualdade de gêneros é um assunto que está em voga. Muito se discute, nas comunidades nacional e internacional, sobre os efeitos das disparidades para homens e (especialmente) mulheres em todas as esferas de suas vidas sociais e privadas. O trabalho, como não poderia deixar de ser, também é incluído na pauta de debates, comumente relacionado ao gender pay gap (diferença de remuneração entre os gêneros, em tradução livre). Os dados internacionais demonstram que houve significativa evolução no último século, mas ainda há um longo caminho para que se atinja a igualdade de fato. No tocante às relações de trabalho, o discurso discriminatório continua a ser propagado abertamente no Brasil, inclusive por figuras públicas sob permanente observação popular, como o atual presidente da República Jair Bolsonaro. E, ainda que haja alguma repercussão negativa quanto a essas falas, não são suficientes para gerar uma reprovação maciça da população. Assim, paradoxalmente, a inegável evolução do movimento feminista não foi suficiente para realmente distanciar esse tipo de declaração daquelas realizadas no início do século XX, à época da discussão do Código de Trabalho de 1917, propagando a sensação de que há, de certa forma, resistência ou até estagnação quanto à valorização da mulher no trabalho.

Ainda que o Brasil conte com belíssimo arcabouço de normas constitucionais e infraconstitucionais que pregam a igualdade entre todas as pessoas, bem como tenha se comprometido com as mais relevantes normas internacionais sobre a igualdade de gêneros, a discriminação se encontra enraizada em todos os setores sociais do país, inclusive os Poderes Legislativo e Judiciário. Nesse contexto, o estereótipo de gênero é um assunto específico e menos explorado que merece atenção. Tanto é verdade que o EACDH (2013) identificou que, apesar de a aplicação do estereótipo de gênero de forma injusta (wrongful gender stereotyping) ser uma causa disseminada de violação aos diretos humanos, tais estereótipos são regularmente ignorados ou mal identificados e raramente ocorre uma discussão aprofundada sobre as inúmeras formas em que eles prejudicam as mulheres.

Assim, primeiramente, é importante definir claramente o estereótipo de gênero como a "visão ou percepção generalizada sobre atributos ou características que são ou devem ser possuídas por homens e mulheres, ou papéis que devem ser desempenhados por homens e mulheres" (EACDH, 2013, p. 8). Já o termo "gender stereotyping" (estereotipar com base em gênero, em tradução livre) refere-se à "prática de determinar a uma mulher ou a um homem atributos, características ou papéis específicos simplesmente em razão de 
pertencerem ao gênero feminino ou masculino" (Cook \& Cusack, 2010, p. 20), que é prejudicial quando "limita sua capacidade de desenvolver suas habilidades pessoais, perseguir suas carreiras profissionais e fazer escolhas sobre suas vidas e planos de vida" (EACDH, 2013, pp. 19-20). Os estereótipos de gênero são subclassificados por Cook \& Cusack (2010) em quatro espécies: estereótipo de sexo (sobre atributos físicos, biológicos, emocionais e cognitivos de homens e mulheres), estereótipo sexual (sobre o comportamento sexual de homens e mulheres); estereótipo de papel de sexo (sobre os papéis que homens e mulheres devem desempenhar na sociedade); e estereótipos combinados (aplicados na intersecção de duas ou mais espécies acima). Para o presente estudo, os estereótipos de sexo e papel de sexo têm maior relevância.

$\mathrm{O}$ ordenamento jurídico brasileiro é repleto de normas que promovem a igualdade e combatem a discriminação; entretanto, não há menção específica quanto a estereótipos de gênero. Nada obstante, o Brasil ratificou e se obrigou a seguir os ditames de algumas convenções internacionais sobre o tema, especialmente a Convenção sobre a Eliminação de Todas as Formas de Discriminação contra a Mulher, cuja interpretação permite concluir que "leis, regulamentos, usos e práticas baseados na ideia da inferioridade ou superioridade de qualquer dos sexos ou em funções estereotipadas de homens e mulheres devem ser modificados ou derrogados" (Cook \& Cusack, 2010, p. 5). Em apartado, a mesma Convenção trata da adoção de medidas especiais de caráter temporário destinadas a alcançar a igualdade de fato entre homens e mulheres sem que possam, de nenhuma maneira, implicar na manutenção de normas desiguais ou separadas. Assim, a intenção é que essas medidas cessem quando os objetivos de igualdade de oportunidade e tratamento houverem sido alcançados. Destarte, “a contínua análise da legislação pátria é necessária para compreender quais normas protetoras do trabalho da mulher são justificáveis, separando os critérios legítimos de diferenciação de outros critérios não legítimos" (Mello, 2009, p. 11), quais acabam por perpetuar estereótipos de gênero e quais se classificam como ações afirmativas de caráter temporário e necessário a nivelar desigualdades históricas entre os gêneros.

Pois bem. A legislação protetora do trabalho da mulher, objeto deste estudo, inclui as normas sobre a saúde e segurança do trabalho (duração do trabalho, períodos de descanso e métodos e locais de trabalho); normas de proteção à maternidade; normas sobre a discriminação da mulher no mercado de trabalho; e se relaciona, tangencialmente, com normas previdenciárias correlatas (salário maternidade e tempo de aposentadoria). A análise dessas normas ao longo das últimas décadas permitiu a identificação de algumas 
tendências: o movimento de subtração das normas protetoras (ou seja, exclusão de normas diferenciadoras do ordenamento jurídico); o movimento de alteração do sujeito das normas protetoras (especialmente no tocante às normas de proteção à maternidade, cuja análise e proteção passou a focar no nascituro, criança ou adolescente ao invés da mulher); e, finalmente, o movimento de expansão das normas protetoras (para que passem a abarcar tanto mulheres quanto homens).

Ante a esses cenários perspectivo e contemporâneo, foram traçados paralelos entre a legislação protetiva do trabalho da mulher e os estereótipos de sexo e de papel de sexo. As principais intersecções foram verificadas entre (a) as normas de saúde e segurança e estereótipo de gênero; e (b) as normas de proteção à maternidade, bem como normas previdenciárias, e o estereótipo de papel do sexo. Entretanto, analisando individualmente os dispositivos específicos de cada grupo, alguns não se encaixam de forma tão estanque.

A única norma classificada como estritamente relacionada com o estereótipo de sexo é o artigo 390 da CLT, que proíbe o emprego de força muscular da mulher para além de 20 (vinte) quilos em esforço contínuo e 25 (vinte e cinco) quilos para o trabalho ocasional, sendo o limite para homens igual a 60 (sessenta) quilos, nos termos do artigo 198 Consolidado. Por seu turno, o estereótipo de papel de sexo pode ser identificado em diversas previsões, tais quais a licença maternidade (e, por consequência, o salário maternidade), tanto por sua extensão substancialmente superior à licença paternidade, quanto por sua garantia até mesmo para mães adotantes que não necessitam de recuperação física no pós-parto, além de pais, em caso de ausência da figura materna.

A estabilidade gestante, que visa proteger o nascituro, também é eivada de estereótipo de papel do sexo, considerando a mulher unicamente responsável pelos cuidados (e gastos) do feto ou recém-nascido. Entretanto, é curioso notar que essa norma foge ligeiramente ao simples estereótipo de mulher-cuidadora e homem-provedor, pois ambos papéis são de certa forma condensados apenas no gênero feminino, visto que não se considera o papel do homem na estabilidade financeira do lar durante a gestação e pósparto.

A lactação, em primeira análise, é estritamente biológica e indissociavelmente relacionada com a figura feminina; e, de maneira relacionada, o artigo 389, parágrafo $1^{\circ} \mathrm{da}$ CLT prevê a obrigação do empregador de fornecer local para guarda dos filhos, em estabelecimentos com mais de 30 (trinta) mulheres com mais de 16 (dezesseis) anos, no período da amamentação. Entretanto, não há nada que impeça que a genitora amamente seu filho, no período legal, lançando mão de métodos artificias por conveniência ou 
necessidade - o que também poderia ser feito pelo pai da criança. Também não se prevê a possibilidade de a mulher trabalhar em estabelecimento com menos de 30 (trinta) empregadas, mas o homem sim, hipótese na qual faria sentido que este último pudesse alimentar o recém-nascido. Assim, vislumbra-se também a presença do estereótipo do papel do sexo, posto que o direto (e, em contraponto, a obrigação) é estendido apenas ao gênero feminino.

$\mathrm{O}$ repouso aos domingos em maior frequência para as mulheres comerciárias também tem evidente carga do estereótipo do papel de sexo, ainda que não seja relacionada com proteção à maternidade, pois a norma não privilegia o descanso biológico da mulher, que poderia ocorrer em qualquer dia da semana; mas, sim, a sua convivência social e familiar aos dias de domingo, independentemente de ser mãe ou não.

Finalmente, o estereótipo de papel do sexo também se manifesta na previsão de aposentadoria para mulher com menos idade do que o homem, que cria uma espécie de compensação pela acumulação histórica e social, por aquelas, dos trabalhos remunerados e não remunerados. Ademais, apenas para que não passe despercebido, vale dizer que não se vislumbra a presença do estereótipo de papel de sexo nas normas de proteção da gestante e lactante em ambiente insalubre, porque estritamente ligadas à sua condição biológica e transitória, além do que a norma não se estende a outras mulheres que não estejam na mesma condição.

Há, ainda, as normas que se encaixam no conceito de ações afirmativas, no sentido de que podem ser compreendidas como não somente pelo prisma retrospectivo - no sentido de aliviar a carga de um passado discriminatório -, mas também prospectivo - no sentido de fomentar a transformação social, criando uma nova realidade (Piovesan, 2014). Dentre aquelas analisadas, são classificadas como tais as normas sobre a discriminação da mulher no mercado de trabalho previstas na CLT e na Lei 9.029/1995. As ações afirmativas, ainda que tenham alguma carga de estereótipos de gênero, são justificáveis para que se acelere o atingimento da igualdade de fato. Já as normas que perpetuam estereótipos de gênero não colaboram e até, por vezes, atrapalham a evolução desejável de acordo com os preceitos constitucionais e convencionais.

Assim, para que servissem de inspiração e modelo, foram buscadas as melhores práticas internacionais, tanto em recomendações de órgãos internacionais, quanto na experiência de países que são classificados como precursores na concretização da igualdade de gênero. Em contraponto, e para demonstrar a necessidade de avanços, foram analisados os resultados da discriminação contra as mulheres e da perpetuação do estereótipo de 
gênero no mercado de trabalho brasileiro. Na sequência, foram apresentadas alternativas para o nivelamento de direitos entre os gêneros partindo das mesmas tendências já observadas nas últimas décadas.

A subtração de direitos, embora já tenha ocorrido historicamente, não parece uma alternativa viável em atenção ao princípio da vedação ao retrocesso e ao princípio da proporcionalidade. A alteração do sujeito das normas protetoras, ainda que valiosa à discussão e ainda que tenha o poder de, até certa medida, afastar o estereótipo de papel de sexo da mulher, apenas se aplica a normas relacionadas à proteção à maternidade e não tem o condão de, efetivamente, nivelar os direitos de homens e mulheres. Por seu turno, a expansão de direitos garantidos às mulheres aos homens certamente traria críticas por diversos setores sociais e governamentais, mas se demonstra como a forma mais ajustada de proteção e promoção da igualdade almejada pela Constituição Federal e pelas normas internacionais ratificadas pelo Brasil. É bem verdade que o nivelamento ideal seria simplesmente interpretar todas as normas protetoras de forma absolutamente paritária aos homens, mas há de se reconhecer que ao menos a paulatina extensão de direitos seria bastante valorosa, pois é importante que as discrepâncias entre homens e mulheres no mercado de trabalho sejam constantemente reduzidas, e não ampliadas ou restem estagnadas.

O presente estudo se propôs a responder as seguintes questões principais: (i) as normas que diferenciam o trabalho do homem e da mulher têm poder de transformação social, ou perpetuam status quo da desigualdade e do estereótipo de gênero?; e (ii) tais normas são alinhadas com a ratio legis da Constituição Federal e das convenções internacionais ratificadas pelo Brasil, bem como com as melhores práticas internacionais para atingimento da igualdade de gênero?

Conclui-se que as normas que perpetuam o estereótipo de gênero, acima mencionadas, não tem poder de transformação social, mas apenas mantêm o status quo. Já as normas classificadas como ações afirmativas têm o potencial de transformação social e aceleração do atingimento da igualdade de fato, desde que evidentemente acompanhadas de efetiva aplicação, fiscalização e sanção, em caso de descumprimento.

Conclui-se, ainda, que essas normas não estão alinhadas com a ratio legis da Constituição Federal e das convenções internacionais ratificadas pelo Brasil, bem como com as melhores práticas internacionais. Nada obstante tenha havido relevante evolução nas últimas décadas, a legislação nacional ainda tem um longo trajeto para que seja possível 
alcançar (ou, ao menos, constantemente avançar na luta por) uma sociedade livre, justa, solidária e sem discriminações, na qual a autodeterminação dos indivíduos se sobressaia a padrões pré-determinados de características, comportamentos ou funções. 


\section{REFERÊNCIAS}

ADATTI, Laura. Maternity and Paternity at Work / Law and practice around the world. OIT, 2014. Disponível em http://www.ilo.org/wcmsp5/groups/public/--dgreports/---dcomm/---publ/documents/publication/wcms_242615.pdf

ALEXY, Robert. Teoria dos direitos fundamentais. Tradução de Virgílio Afonso da Silva. $2^{\mathrm{a}}$ edição. São Paulo: Malheiros, 2011.

ALMEIDA, Amador Paes de. CLT Comentada. $9^{a}$ edição rev. atual. e ampl. São Paulo: Saraiva, 2015.

ANDREUCCI, Ana Cláudia Pompeu Torezan. Igualdade de Gênero e Ações Afirmativas: Desafios e Perspectivas para as Mulheres Brasileiras Pós Constituição Federal De 1988. $1^{\text {a }}$ edição. São Paulo: LTr, 2012.

ANDREUCCI, Ana Cláudia Pompeu Torezan. Por uma efetiva construção da igualdade de gênero no ordenamento jurídico brasileiro: análise da necessária revisão do tratamento diferenciado às mulheres nas aposentadorias por idade e por tempo de contribuição na Constituição Federal de 1988. 30/11/2010. Tese de Doutorado Pontifícia Universidade Católica (PUC) de São Paulo.

BARROS, Alice Monteiro de. Curso de Direito do Trabalho. $9^{a}$ edição. LTr, São Paulo, 2013.

BARROS, Alice Monteiro de. Protecionismo legal e os efeitos no mercado de trabalho da mulher in Genesis Revista de Direito do Trabalho. Curitiba, no 13, p. 001112, janeiro de 1994.

BEAUDOnNET, Xavier (ed.). Direito Internacional do Trabalho e Direito Interno: Manual de formação de juízes, juristas e docentes em direito. Turim: Centro Internacional de Formação da OIT, 2011. 
BRASIL. Decreto Lei $n^{0}$ 2.848, de 7 de dezembro de 1940: Código Penal. Disponível em: http://www.planalto.gov.br/ccivil 03/Decreto-Lei/Del2848.htm. Acesso em: 10 de junho de 2018.

BRASIL. Decreto Lei no 5.452, de 1 de maio de 1943: Consolidação das Leis do Trabalho. Disponível em: <http://www.planalto.gov.br/ccivil/Decreto-Lei/Del5452.htm>. Acesso em: 15 de outubro de 2018.

BRASIL. Constituição Federal de 1988. Disponível em: $<$ http://www.planalto.gov.br/ccivil_03/constituicao/constitui\%C3\%A7ao.htm>. Acesso em: 07 de outubro de 2018.

BRASIL. Lei $\mathbf{n}^{0}$ 8.213, de 24 de julho de 1991. Disponível em: https://www.planalto.gov.br/ccivil_03/Leis/L8213cons.htm. Acesso em: 12 de setembro de 2018.

BRASIL. Lei $\mathrm{n}^{\mathbf{0}}$ 9.799, de 26 de maio de 1999. Disponível em: http://www.planalto.gov.br/CCIVIL_03/Leis/L9799.htm. Acesso em: 5 de setembro de 2018.

BRASIL. Lei n⿳0 10.172, de 9 de janeiro de 2001, (Plano Nacional De Educação). Disponível em: https://www.planalto.gov.br/ccivil_03/leis/leis_2001/110172.htm. Acesso em: 2 de setembro de 2018 .

BRASIL. Decreto $N^{0}$ 4.377, de 13 de setembro de 2002. Disponível em: http://www.planalto.gov.br/ccivil_03/decreto/2002/d4377.htm. Acesso em: 14 de setembro de 2018.

BRASIL. Lei $n^{0}$ 11.340, de 7 de agosto de 2006, (Lei Maria da Penha). Disponível em: http://www.planalto.gov.br/ccivil_03/_ato20042006/2006/lei/111340.htm. Acesso em: 19 de julho de 2018. 


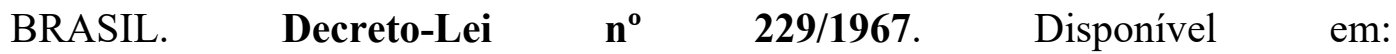
http://www.planalto.gov.br/ccivil 03/decreto-lei/Del0229.htm. Acesso em: 19 de setembro de 2018.

BRASIL. Lei $\mathbf{n}^{\mathbf{0}}$ 12.812, de 16 de maio de 2013. Disponível em: http://www.planalto.gov.br/ccivil 03/_Ato2011-2014/2013/Lei/L12812.htm. Acesso em: 5 de setembro de 2018.

BRASIL. Congresso Nacional. Senado Federal. Projeto de Lei da Câmara $n^{0} 76$ de 2014. Disponível em:

https://legis.senado.leg.br/sdleggetter/documento?dm=3505097\&ts=1543030480834\&disposition=inline. Acesso em: 11 de novembro de 2018 .

BRASIL. Lei Complementar $n^{\circ}$ 146, de 25 de junho de 2014. Disponível em: http://www.planalto.gov.br/ccivil 03/LEIS/LCP/Lcp146.htm. Acesso em: 8 de outubro de 2018.

BRASIL. Lei $\mathbf{n}^{\circ}$ 13.467, de 13 de julho de 2017., (Reforma Trabalhista). Disponível em: http://www.planalto.gov.br/ccivil_03/Decreto-Lei/Del5452.htm. Acesso em: 06 de junho de 2018.

BRASIL. Medida Provisória No 870, de $1^{\text {o }}$ de janeiro de 2019. Disponível em: http://www.planalto.gov.br/ccivil_03/_Ato2019-2022/2019/Mpv/mpv870.htm. Acesso em: 5 de Janeiro de 2019.

CONTRAF \& FEBABAN. Convenção Coletiva de Trabalho 2016/2018. (2018). Disponível em: http://spbancarios.com.br/sites/default/files/cct/arquivo/1181_cct_2016_2018.pdf. Acesso em: 13 de outubro de 2018.

COMISSÃO INTERAMERICANA DE DIREITOS HUMANOS. Organização dos Estados Americanos. Relatório Anual 2000. Relatório № 54/01. Caso 12.051. Maria Da Penha Maia Fernandes. Brasil. 4 de abril de 2001. Disponível em https://www.cidh.oas.org/annualrep/2000port/12051.htm. 
COMMITTEE ON THE ELIMINATION OF DISCRIMINATION AGAINST WOMEN. "Consideration of reports submitted by States parties under article 18 of the Convention on the Elimination of All Forms of Discrimination against Women". Combined initial, second, third, fourth and fifth periodic reports of States parties, Brazil. Disponível em https://daccess-ods.un.org/TMP/923150.703310966.html.

\section{COMMITTEE ON THE ELIMINATION OF DISCRIMINATION AGAINST} WOMEN. "Consideration of reports submitted by States parties under article 18 of the Convention on the Elimination of All Forms of Discrimination against Women". Sixth periodic reports of States parties, Brazil. Disponível em https://daccessods.un.org/TMP/8176031.1126709.html.

COMPARATO, Fábio Konder. A afirmação histórica dos direitos humanos. $7^{\mathrm{a}}$ edição. São Paulo: Saraiva, 2010.

COOK, Rebecca J. Human Rights of Women: National and International Perspectives. University of Pennsylvania Press. 1994.

COOK, Rebecca J. e HOWARD, Susannah. “Accommodating Women's Differences under the Women's Anti-Discrimination Convention”. Emory Law Journal, Vol. 56, N. 4, PP. 1039-1091. 2007.

COOK, Rebecca J. \& CUSACK, Simone. Gender Stereotyping: Transnational Legal Perspectives. University of Pennsylvania Press. 2010.

DE SCHUTTER, Olivier. International Human Rights Law: Cases, Materials and Commentary. 2a edição. Cambridge University Press. 2014.

DELGADO, Maurício Godinho. Curso de Direito do Trabalho. $14^{\mathrm{a}}$ edição. São Paulo: LTr, 2015.

DNSHT - Departamento Nacional de Segurança e Higiene do Trabalho. Portaria 1/1969. Diário Oficial da União. 15 de janeiro de 1969. 
EACDH - Escritório do Alto Comissário das Nações Unidas para os Direitos Humanos. Gender Stereotyping as a human rights violation. Outubro, 2013. Disponível em http://www.ohchr.org/EN/Issues/Women/WRGS/Pages/GenderStereotypes.aspx. Acesso em: 10 de Junho de 2018.

FONTES, Ana Cristina Magalhães. O papel da Justiça do Trabalho na promoção da Igualdade de Gênero: Um olhar a partir do trabalho decente. 2013. Dissertação de Mestrado - Universidade Presbiteriana Mackenzie.

FÓRUM ECONÔMICO MUNDIAL. The Global Gender Gap Report. 2016. Disponível em: https://www.weforum.org/reports/the-global-gender-gap-report-2016. Acesso em: 15 de Junho de 2018.

. The Global Gender Gap Report. 2017. Disponível em: https://www.weforum.org/reports/the-global-gender-gap-report-2017. Acesso em: 15 de Junho de 2018.

GONÇALVES, Tamara Amoroso. Direitos Humanos das Mulheres e a Comissão Interamericana de Direitos Humanos. São Paulo: Saraiva, 2013.

GRIMSHAW, Damian \& RUBERY, Jill. The motherhood pay gap: A review of the issues, theory and international evidence. Working Paper .International Labour Office, 2015. Disponível em http:/www.ilo.org/wcmsp5/groups/public/---dgreports/--gender/documents/publication/wcms 371804.pdf

HUFFPOST. Bolsonaro Afirmou que não Empregaria Mulher com mesmo Salário de Homem. 18 de agosto de 2018. https://www.huffpostbrasil.com/2018/08/18/bolsonaro-afirmou-sim-que-nao-empregariamulher-com-mesmo-salario-de-homem_a_23504540/. Acesso 02/01/2019.

HUSEK, Carlos Roberto. Curso básico de direito internacional público e privado do trabalho. $2^{\mathrm{a}}$ edição. São Paulo: LTr, 2011. 
KNAUL, Gabriella. Report of the Special Rapporteur on the independence of judges and lawyers. UN Doc. A/HRC/17/30. 29 de abril de 2011. Disponível em: https://documents-dds-

ny.un.org/doc/UNDOC/GEN/G11/130/15/PDF/G1113015.pdf?OpenElement. Acesso em: 21 de agosto de 2018.

IBGE. Estatísticas de Gênero - Indicadores Sociais das Mulheres no Brasil. 2018. Disponível em: https://biblioteca.ibge.gov.br/visualizacao/livros/liv101551_informativo.pdf. Acesso em: 2 de junho de 2018.

IKARA, Daniela. Direito e ações afirmativas: princípio da dignidade e concepção de ser humano in Direito à Diferença: aspectos institucionais e instrumentais de proteção às minorias e aos grupos vulneráveis, Volume 3. JUBILUT, Liliana Lyra, BAHIA, Alexandre Gustavo Melo Franco e MAGALHÃES, José Luiz Quadros de. São Paulo: Saraiva, 2013.

MACHADO, Costa (org.). CLT Interpretada: artigo por artigo, parágrafo por parágrafo. $8^{\mathrm{a}}$ edição. Barueri: Manole, 2017.

MALLET, Estevão. Igualdade, Discriminação e Direito do Trabalho. São Paulo, 2008. Disponível em www.revistas.usp.br/rfdusp/article/view/67804/70412

MALLET, Estêvão. Igualdade e discriminação em direito do trabalho. $1^{\text {a }}$ edição. São Paulo: LTr, 2013.

MALLET, Estêvão. Ensaio sobre a interpretação das decisões judiciais. São Paulo: LTr, 2009.

MANUS, Pedro Paulo Teixeira. Direito do trabalho. $15^{\text {a }}$ edição. São Paulo: Editora Atlas, 2014.

MELLO, Celso Antônio Bandeira de. O conteúdo jurídico do princípio da igualdade. $3^{\text {a }}$ edição. São Paulo: Malheiros Editores, 2009. 
MELLO, Celso Antonio Bandeira de. Eficácia das normas constitucionais e direitos sociais. São Paulo: Malheiros, 2009.

MINISTÉRIO DA DEFESA. Primeiras Mulheres Ingressam na Carreira de Oficial Combatente do Exército. Disponível em: http://www.eb.mil.br/web/midiaimpressa/o-que-vai-pela-forca/-/asset publisher/FPJORbAA3k44/content/primeirasmulheres-ingressam-na-carreira-de-oficial-combatente-do-exercito. Acesso em: 14 de julho de 2018 .

NOVAIS, Denise Passelo Valente. Discriminação da Mulher e o Direito do Trabalho. Da Proteção à Promoção da Igualdade. $1^{\text {a }}$ edição. São Paulo: LTr, 2005.

OIT - Organização Internacional do Trabalho. C171 - Night Work Convention, 1990 (No. 171). Disponível em: https://www.ilo.org/dyn/normlex/en/f?p=NORMLEXPUB:12100:0::NO::P12100_INSTR UMENT_ID:312316. Acesso em: 14 de outubro de 2018.

OIT - Organização Internacional do Trabalho. Women's empowerment: 90 years of ILO action! Disponível em http://www.ilo.org/gender/Events/Campaign20082009/WCMS 104905/lang--en/index.htm.

OIT - Organização Internacional do Trabalho. Maternity, Paternity at Work: Baby steps towards achieving big results. Disponível em http://www.ilo.org/wcmsp5/groups/public/---dgreports/--gender/documents/briefingnote/wcms 410183.pdf

OIT - Organização Internacional do Trabalho. Pay Equality: A key driver to gender equality. Disponível em http://www.ilo.org/wcmsp5/groups/public/---dgreports/--gender/documents/briefingnote/wcms_410196.pdf

ONU. Declaração Universal dos Direitos Humanos. 1948. Disponível em: https://declaracao1948.com.br/declaracao-universal/declaracao/. Acesso em: 23 de maio de 2018. 
ONU. Convenção Sobre a Eliminação de Todas as Formas de Discriminação Contra a $\quad$ Mulher. $1979 . \quad$ Disponível em: https://unesdoc.unesco.org/ark:/48223/pf0000139389. Acesso em: 23 de maio de 2018.

ONU MULHERES. General Survey on Night Work and Women in Industry. 2004. Disponível em http://www.ilo.org/global/standards/information-resources-andpublications/WCMS_164145/lang--en/index.htm.

SARLET, Ingo. "A assim designada proibição de retrocesso social e a construção de um direito constitucional comum latino-americano". In. Biblioteca Digital Revista Brasileira de Estudos Constitucionais - RBEC, Belo Horizonte, ano 3, n. 11, jul. 2009.

STF - Superior Tribunal Federal. Recurso Especial: RE658312 SC. Relator: Dias Toffoli. DJ: 27/11/2014. JusBrasil, 2015. Disponível em: https://stf.jusbrasil.com.br/jurisprudencia/311630607/recurso-extraordinario-re-658312santa-catarina. Acesso em: 6 de setembro de 2018.

PIOVESAN, Flávia. Código de Direito Internacional dos Direitos Humanos Anotados. São Paulo: DPJ Editora, 2008.

PIOVESAN, Flávia. Direitos humanos e o direito constitucional internacional. $12^{\mathrm{a}}$ edição. São Paulo: Saraiva, 2011.

PIOVESAN, Flávia. Temas de direitos humanos. $7^{a}$ edição. São Paulo: Saraiva, 2014.

SAAD, Eduardo Gabriel. Consolidação das Leis do Trabalho: comentada. $40^{\mathrm{a}}$ edição. atual. e rev. e ampl. por José Eduardo Duarte Saad, Ana Maria Saad Castello Branco. São Paulo: LTr, 2007

SILVA, Homero Batista Mateus da. CLT comentada. $1^{\text {a }}$ edição. São Paulo: Editora revista dos Tribunais, 2016. 
SILVA, Homero Batista Mateus da. Curso de direito do trabalho aplicado / Segurança e Medicina do Trabalho / Trabalho da Mulher e do Menor. $2^{\mathrm{a}}$ edição. Rio de Janeiro: Editora Elsevier, 2015.

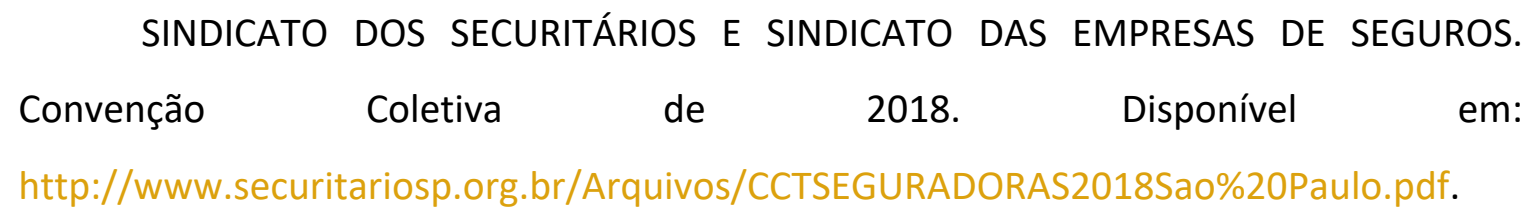
Acesso em: 13 de outubro de 2018.

SUSSEKIND, Arnaldo. Instituições de Direito do Trabalho, volume II / Arnaldo Sussekind... (et al.). 21 a edição atualizada por Arnaldo Sussekind e João Lima Teixeira Filho. São Paulo: LTr, 2003. Outros autores: Délio Maranhão, Segadas Vianna, Lima Texeira.

TST - Tribunal Superior do Trabalho. PROC. No TST-IIN-RR-1.540/2005-04612-00.5. Relator: Ives Gandra Martins Filho. DJ: 13/02/2009. JornalJurid, 2008. Disponível em: https://www.jornaljurid.com.br/noticias/mulher-intervalo-de-15-minutos-antes-delabor-em-sobrejornada-constitucionalidade-do-art-384-da-clt-em-face-do-art-5o-i-da-cf. Acesso em: 5 de setembro de 2018.

UNIÃO EUROPEIA. "Tratado que Estabelece uma Constituição para a Europa". In Jornal Oficial da União Europeia, 2005.

VIEIRA, Regina Stela Corrêa. Saúde e segurança no trabalho das mulheres: a perspectiva de gênero para a proteção e promoção do meio ambiente laboral equilibrado. 218 páginas. Dissertação de Mestrado - Universidade São Paulo.

ZERO HORA. Bolsonaro diz que não teme processos e faz nova ofensa: 'Não merece ser estuprada porque é muito feia'. 10 de dezembro de 2014. Disponível em: https:/gauchazh.clicrbs.com.br/politica/noticia/2014/12/bolsonaro-diz-que-nao-temeprocessos-e-faz-nova-ofensa-nao-merece-ser-estuprada-porque-e-muito-feiacjkf8rj3x00cc01pi3kz6nu2e.html. Acesso em: 15/06/2017. 


\section{ANEXO I}

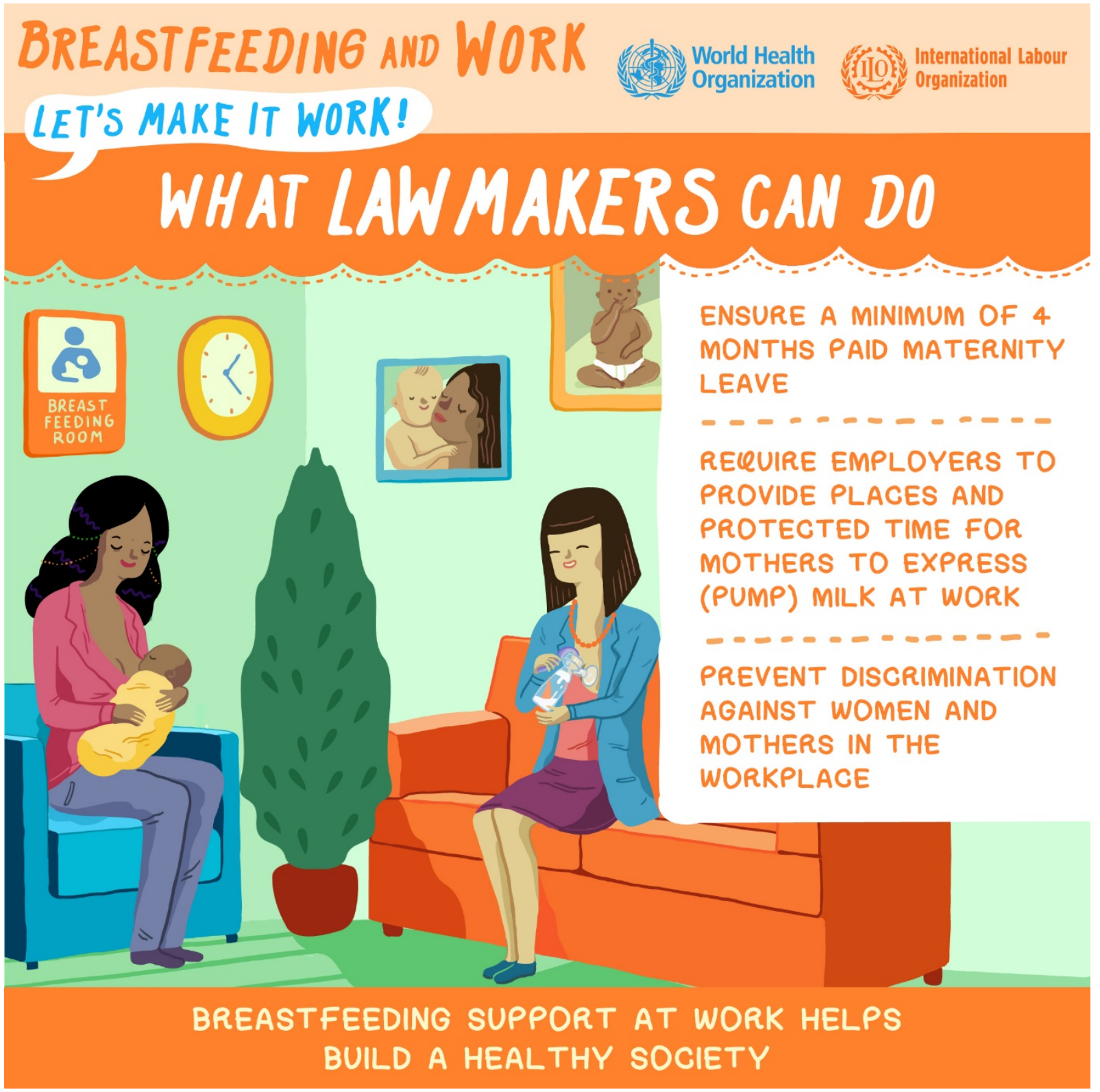




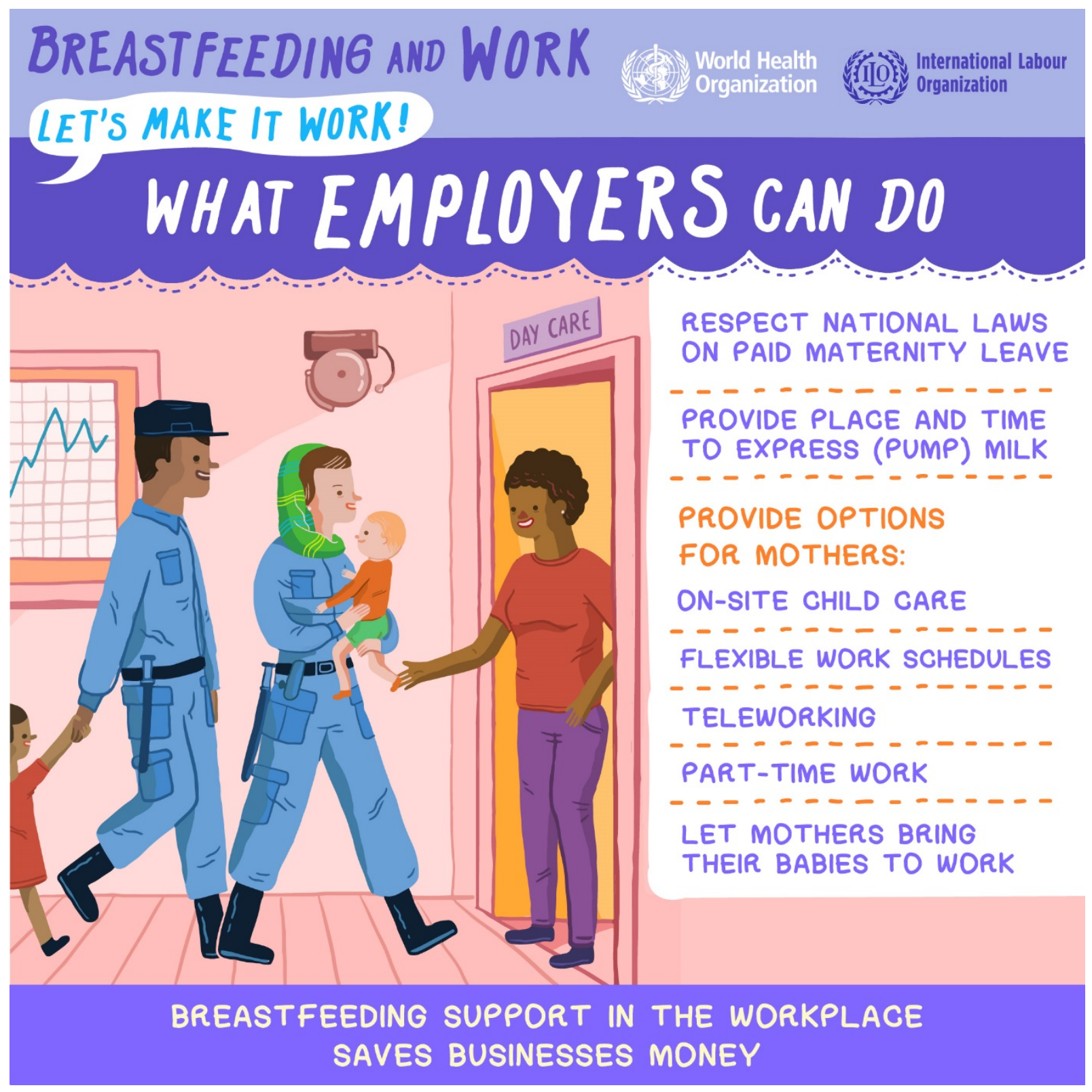




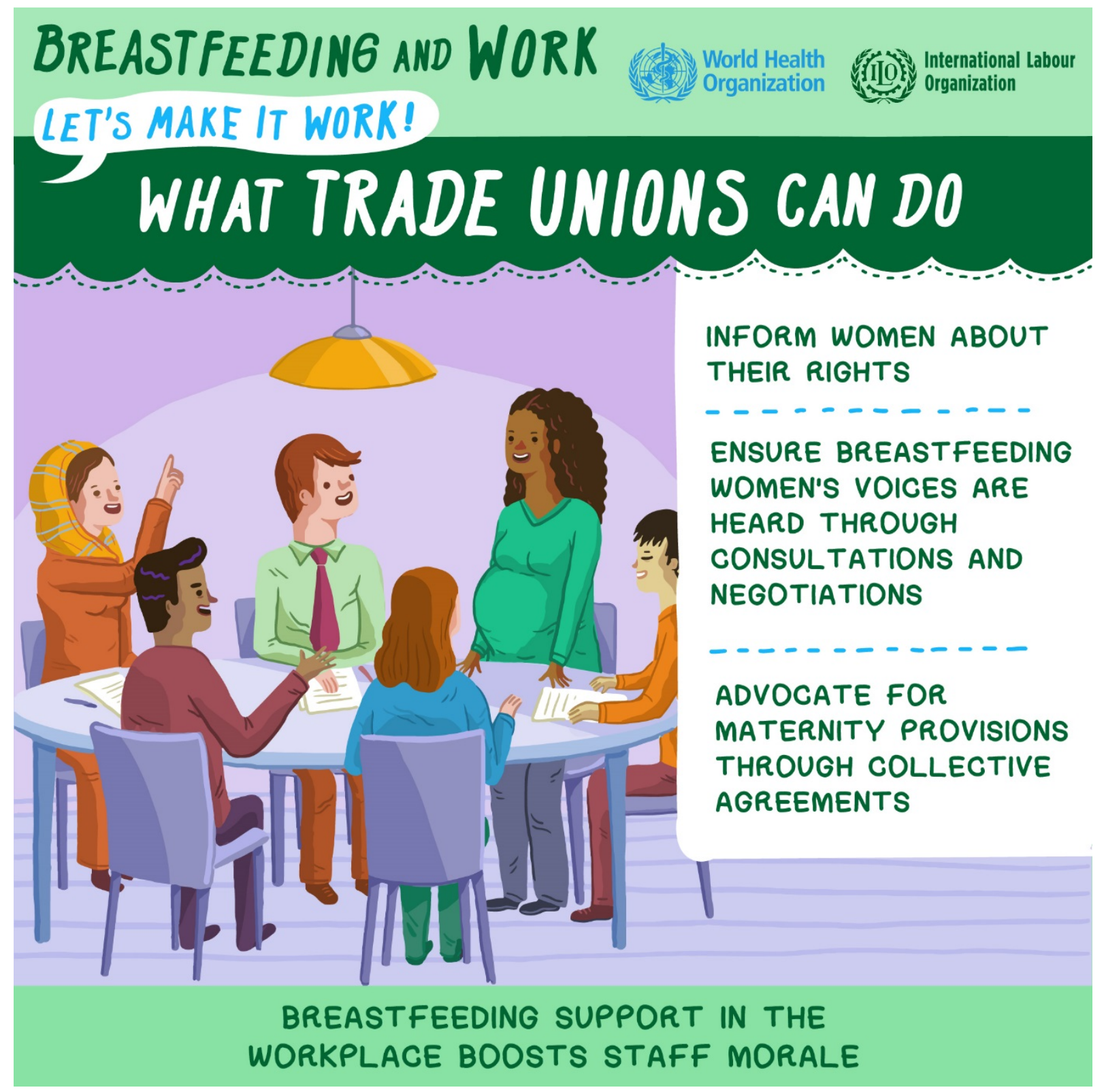




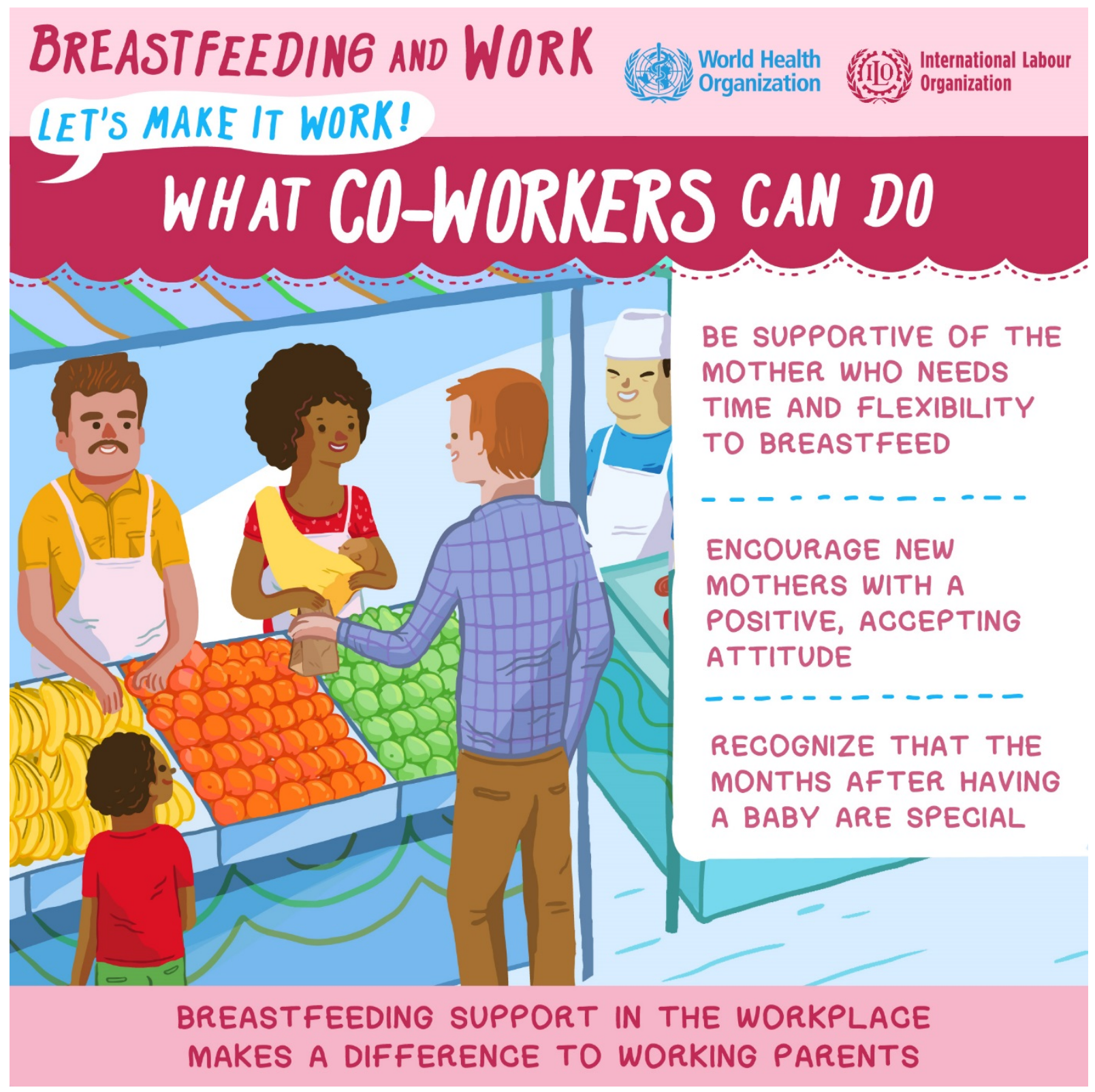

